
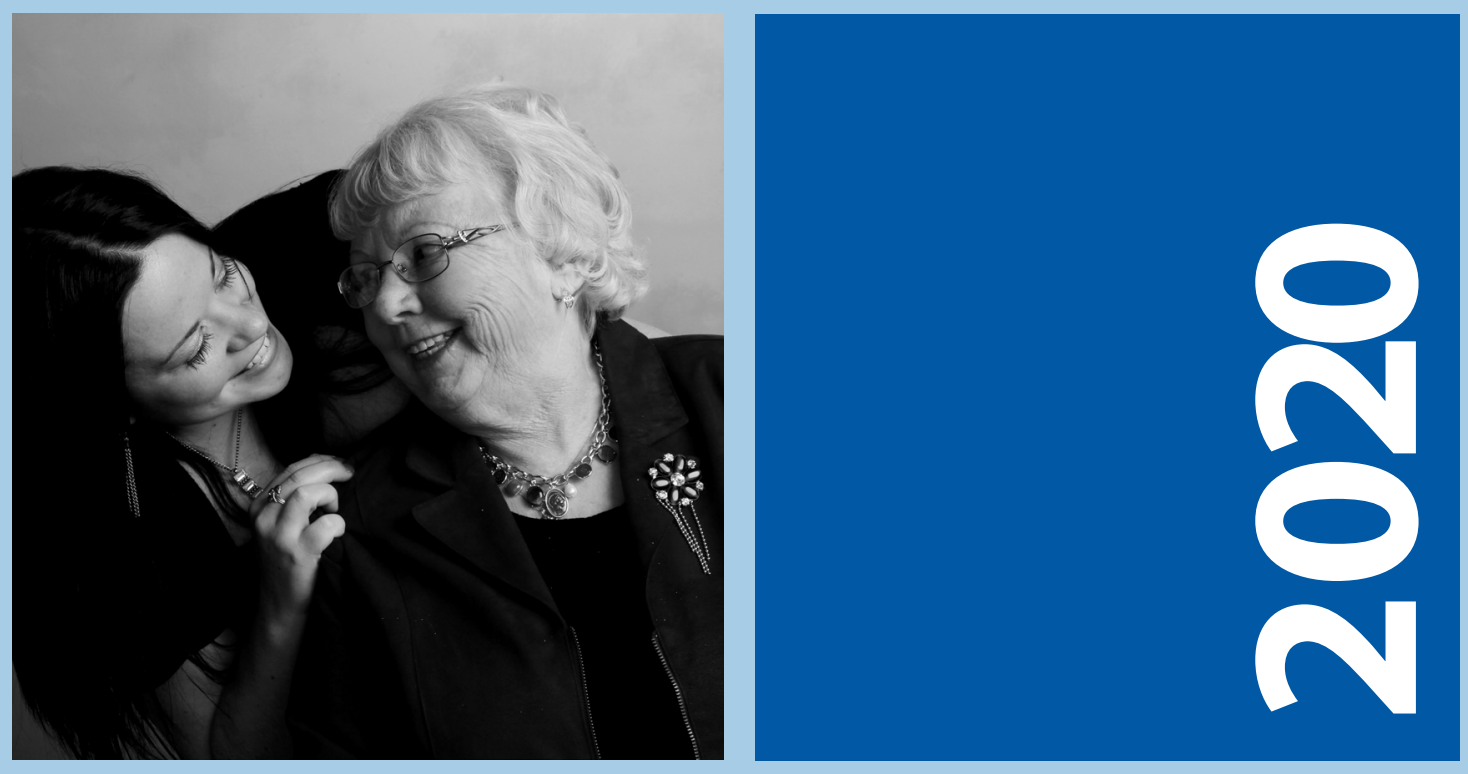

TILDA Report on Population Estimates of Physical Frailty in Ireland to Inform Demographics for Over 50 s in Ireland during the COVID-19 Pandemic

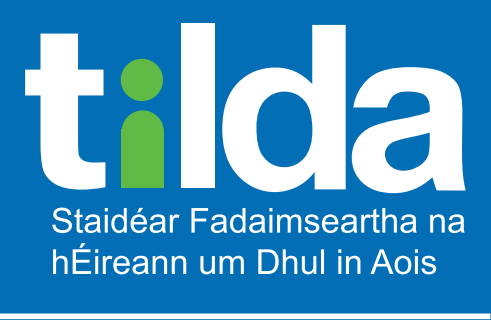

The Irish Longitudinal Study on Ageing 


\section{TILDA Report on Population Estimates of Physical Frailty in Ireland to Inform Demographics for Over 50s in Ireland during the COVID-19 Pandemic}

\footnotetext{
Aisling O'Halloran, Christine McGarrigle, Siobhan Scarlett, Lorna Roe, Roman Romero-Ortuno and Rose Anne Kenny
}

The Irish Longitudinal Study on Ageing

On behalf of the TILDA team

April 2020 
Copyright (C) The Irish Longitudinal Study on Ageing 2020

The Irish Longitudinal Study on Ageing

Trinity College Dublin

Dublin 2

Tel: +35318962509

Email: tilda@tcd.ie

Website: www.tilda.ie

ISBN: 978-1-907894-27-5

https://www.doi.org/10.38018/TildaRe.2020-02 


\section{Acknowledgements}

We would like to acknowledge the vision and commitment of our study funders, the Department of Health, the Health Research Board, Science Foundation Ireland, The Atlantic Philanthropies, and Irish Life plc. We would like to state that any views expressed in this report are not necessarily those of the Department of Health or of the Minister for Health. We would also like to thank the TILDA participants without whom this research would not be possible. 


\section{Contents}

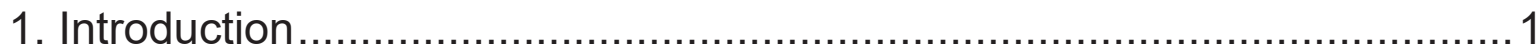

2. Population estimates of adults aged $55+$ years in Ireland - CSO (2016) and TILDA (2018)

3. Physical Frailty Estimates by Age and Sex 5

4. Physical Frailty and Living Alone by Age 8

5. Physical Frailty Estimates by County 10

6. Physical Frailty by Informal Care and Formal Community Supports 15

7. Conclusions 18

8. References 


\section{PHYSICAL FRAILTY IN ADULTS OVER 55 IN IRELAND}

\section{POPULATION PREVALENCE OF FRAILTY}

126,100 ADULTS OVER 55 ARE LIVING WITH FRAILTY

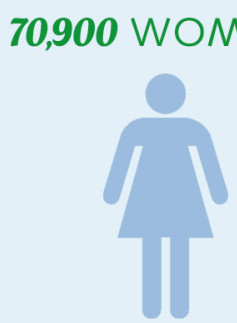

vs

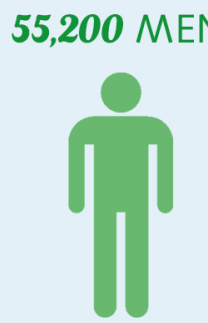

17,600 ADULTS OVER 55 ARE LIVING ALONE WITH FRAILTY

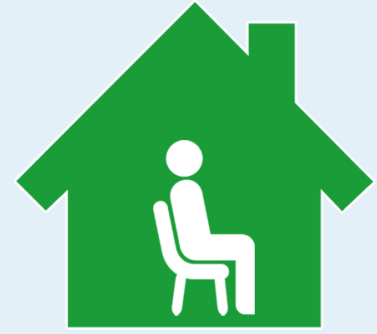

ADULTS OVER 55 LIVING WITH FRAILTY BY COUNTY HIGHEST PREVALENCE

LOWEST PREVALENCE

DUBLIN
CORK
LIMERICK
WEXFORD

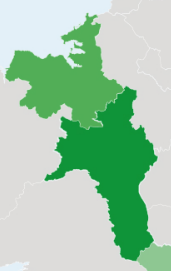

ROSCOMMON

SLIGO

OFFALY

\section{LIVING WITH FRAILTY BY ACCESS TO COMMUNITY SUPPORT SERVICES*}

ADULTS OVER 55

O NO FORMAL OR INFORMAL CARE

72,100

O PUBLIC HOME HELP

12,500

O PUBLIC PERSONAL CARE ATTENDANT

10,800

O PRIVATE HOME HELP/PERSONAL CARE ATTENDANT

10,500

O PUBLIC MEALS ON WHEELS

5,400

O HOME CARE PACKAGE

5,000

TILDA sampling frame does not include dementia or nursing home participants at baseline, these figures may underestimate informal care and formal community supports

For more information please visit www.tilda.ie Supported by 


\section{PHYSICAL FRAILTY IN ADULTS OVER 70 IN IRELAND}

\section{POPULATION PREVALENCE OF FRAILTY}

80,600 ADULTS OVER 70 ARE LIVING WITH FRAILTY

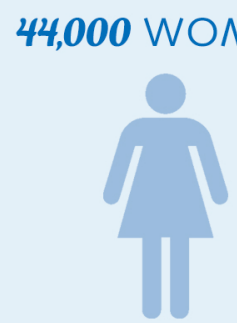

vs

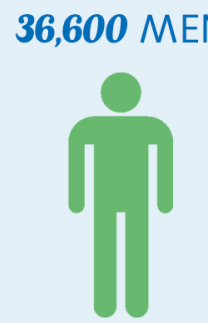

12,200 ADULTS OVER 70 ARE LIVING ALONE WITH FRAILTY

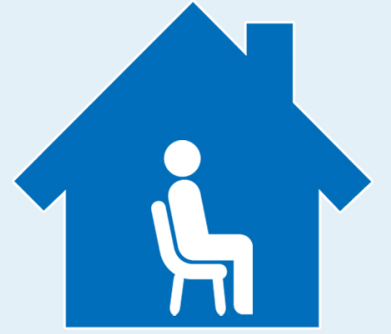

\section{ADULTS OVER 70 LIVING WITH FRAILTY BY COUNTY}

HIGHEST PREVALENCE

DUBLIN

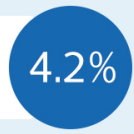

CORK

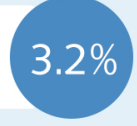

LIMERICK

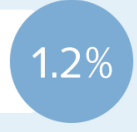

WEXFORD

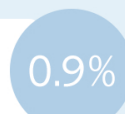

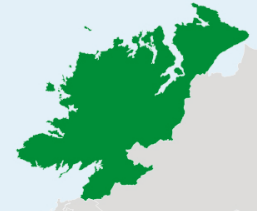

LOWEST PREVALENCE

ROSCOMMON/ DONEGAL

$0.2 \%$

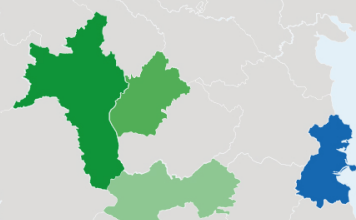

LONGFORD

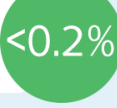

OFFALY

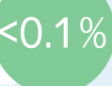

CARLOW

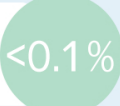

\section{LIVING WITH FRAILTY BY ACCESS TO COMMUNITY SUPPORT SERVICES*}

ADULTS OVER 70

O NO FORMAL OR INFORMAL CARE

44,500

O PUBLIC HOME HELP

9,600

O PUBLIC PERSONAL CARE ATTENDANT

8,200

O PRIVATE HOME HELP/PERSONAL CARE ATTENDANT

7,600

O PUBLIC MEALS ON WHEELS

4,300

O HOME CARE PACKAGE

3,600

'TILDA sampling frame does not include dementia or nursing home participants at baseline, these figures may underestimate informal care and formal community supports

For more information please visit www.tilda.ie Supported by

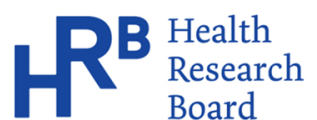
Board $\underset{\substack{\text { Sciecce } \\ \text { ndation }}}{2}$ fl
The
A T L A N T I C

Irish Life 


\section{Key Findings}

- The prevalence of physical frailty ${ }^{1}$ in Ireland increases with advancing age: $11 \%$ in those aged $55+; 15 \%$ in $65+; 19 \%$ in $70+; 25 \%$ in $75+; 35 \%$ in $80+$ and $46 \%$ in $85+$. The equivalent numbers are: 126,100 (55+); 89,500 (65+); 80,600 (70+); 63,900 (75+); $48,800(80+)$; and 31,100 (85+).

- There are more women than men living with frailty: $12.3 \%$ vs. $9.7 \%$ among those aged $55+$, and $20.3 \%$ vs. $17.5 \%$ among those aged $70+$. Of those living with frailty in Ireland, $56.2 \%(70,900)$ aged $55+$ years and $54.7 \%(44,000)$ aged $70+$ years are female.

- Among those aged 55+ years, $10.8 \%(107,100)$ are living alone, of whom $16.1 \%$ $(17,600)$ live alone with frailty. Among those aged $70+$ years, $10.4 \%(43,400)$ are living alone, of whom $28.1 \%(12,200)$ live alone with frailty.

- Among those 55+, frailty as a proportion of the total population of Ireland was highest in Dublin $(2.4 \%)$, Cork (1.7\%), Limerick (0.9\%) and Wexford $(0.5 \%)$.

- Among those $70+$, frailty as a proportion of the total population of Ireland was highest in Dublin (4.2\%), Cork (3.2\%), Limerick (1.2\%) and Wexford (0.9\%).

- Of the 80,600 adults aged $70+$ years living with frailty:

○ $44,500(55.2 \%)$ do not receive any form of informal care or formal community support

○ $24,800(30.8 \%)$ receive informal care from a family member or friend

○ $26,100(32.4 \%)$ receive formal community support services

○ $7,600(9.4 \%)$ pay for Private home help or a personal care attendant

○ 9,600 (12.1\%) receive Public home help

○ 8,200 (10.2\%) receive Public personal care attendant

○ 4,300 (5.3\%) receive Public meals-on-wheels

○ 3,600 (4.5\%) are in receipt of a home care package

$1 \quad$ For the purposes of this report, frailty refers to Fried's Physical Frailty Phenotype. This is defined as 3 or more of the following: self-reported exhaustion, unexplained weight loss, weak grip strength, slow gait speed, and low physical activity. The presence of one or two criteria defines pre-frailty. For further information, see: Linda P. Fried, Catherine M. Tangen, Jeremy Walston, Anne B. Newman, Calvin Hirsch, John Gottdiener, Teresa Seeman, Russell Tracy, Willem J. Kop, Gregory Burke, Mary Ann McBurnie, Frailty in Older Adults: Evidence for a Phenotype, The Journals of Gerontology: Series A, Volume 56, Issue 3, 1 March 2001, Pages M146-M157, https://doi.org/10.1093/gerona/56.3.M146 


\section{Introduction}

\section{$1.1 \quad$ Background}

Frailty is described as a distinctive health state related to the ageing process in which multiple body systems gradually lose their in-built reserves. Older adults living with frailty are at an increased risk of unpredictable deterioration in their health following exposure to insults such as COVID-19 infection $(1,2)$. Frailty is a common condition in older adults, although it is not an inevitable part of the ageing process (3). Frailty can occur at any age but becomes more prevalent with advancing age (4). This association with increasing age has implications for Ireland in terms of the impact of COVID-19 on medically vulnerable adults aged 70 years and over. On March 28th 2020, the Irish Government implemented new HSE 'Guidance on cocooning to protect people over 70 years and those extremely medically vulnerable from COVID-19' (5). In the UK, the National Institute for Health in Care Excellence (NICE) has published rapid covid-19 guidelines for the management of patients in critical care (6). NICE says that all patients, irrespective of COVID-19 status, should on admission to hospital continue to be assessed for frailty. Patients classified as having frailty should then to be put through a process where doctors must consider if critical care is considered appropriate before proceeding. Therefore, frailty is becoming a key concept in healthcare service planning development and delivery for our ageing population $(7,8)$, particularly during the current COVID-19 public health emergency.

Frailty is a dynamic process that changes over time and can be viewed on a continuum. An older person can transition in either direction between the different states of frailty, namely robustness, pre-frailty (an intermediate state) and frailty (9). Robust older people may have some health problems, but in general these problems are being well managed. Older people with pre-frailty are at an increased risk of adverse outcomes but are coping. Individuals living with frailty generally require some support for instrumental and/or basic activities of daily living, have increased susceptibility to infection, take longer to recover from infections and are less likely to recover to previous levels of functional independence. For older adults living with frailty, exposure to a stressor such as infection significantly increases the risk of disability, hospital admission, longer in-patient length of stay, transition to long-term care and death (10). It is highly likely that individuals living with frailty who contract COVID-19 are at greatest risk for admission to hospital, admission to critical and intensive care units and death. Identifying people living with frailty provides an opportunity to prevent this at-risk group from contracting COVID-19 in the community and proactively 
to develop healthcare service planning and delivery for our medically vulnerable population aged $70+$ years $(11)$.

Although frailty is a recognisable and common phenomenon in ageing, it is difficult accurately to define and diagnose. The gold standard for the assessment and management of frailty is the Comprehensive Geriatric Assessment (CGA). CGA is a holistic and interdisciplinary assessment of an individual and has been demonstrated to reduce adverse outcomes including disability, cognitive decline, long-term residential care and death (12). However, CGA is time-consuming and must be carried out by trained clinicians, so is not feasible for rapid triage and admission in acute care settings. Despite a lack of agreement on an internationally accepted and easily administered consensus measure of frailty, several methods of screening are commonly used (13).

This report will provide an overview of the numbers of people aged $55+$ and $70+$ years in Ireland classified by physical frailty status (using Linda Fried's physical frailty phenotype) as captured by TILDA Wave 5 (2018) (1). The physical frailty status is classified by the presence in an individual of five criteria, namely exhaustion/fatigue, unintended weight loss, slow walking speed, muscle weakness and low levels of physical activity $(8,11)$. The presence of none, 1-2 and $\geq 3$ of these criteria indicates that an individual is non-frail, prefrail or frail respectively.

To assist with planning for COVID-19, we have analysed the following to help identify numbers from cohorts based on extant national and international data for at-risk groups such as those living with frailty and pre-frailty; those who live alone; and those who have access to community support services.

TILDA is a longitudinal study on ageing, which at Wave 1 (2009) represented 1:156 people aged 50 and older in Ireland. TILDA collects detailed subjective and objective measures of health, social circumstances and economics every two years. These interviews are delivered in participants' homes using a computer-assisted personal interview (CAPI). Core objective health measures are also collected at each wave in the home, and more detailed health assessments take place at alternate data sweeps in a health assessment centre or in the participant's home. Response rate at Wave 1 was $62 \%$. Wave 1 commenced in 2009, Wave 5 in 2018.

\subsection{Sample}

All estimates are based on data from the most recent Wave 5 of TILDA (collected in 2018, $n=5,147$ respondents); total population estimates are based on figures collected from the most recent CSO Census 2016 data, which reported a total of 1,146,525 people over 55+ 
living in Ireland. It should be noted that the TILDA sampling frame does not include people with dementia at baseline or people living in nursing homes, and as such these data may slightly underestimate prevalence for the total population in Ireland. For estimates of frailty phenotype prevalence, all numbers are calculated based on the presence of the five physical frailty criteria among participants at Wave 5 (2018).

\subsection{Weights}

Weights were used in all cases to make estimates relevant to the general population of over 50s in Ireland. In this instance, longitudinal weights which account for participant attrition between Wave 1 and Wave 5 were used. To calculate these weights, the underlying probability of being included in the computer-assisted personal interview (CAPI) was multiplied by the reciprocal of the probability of participating in all 5 TILDA waves. This probability was calculated using a logistic regression with the following predictors: age, sex, education level, age, marital status, geographic location, smoking status, health insurance, medications, socio-economic stratum, self-rated health, disabilities, depression, employment status, cardiovascular conditions, diabetes, vision, cognitive status and whether a person has wrist or hip fractures. Please note that (i) percentages and numbers are estimates and (ii) due to the application of population weights, weighted estimates for $55+$ and $70+$ are not equivalent to the sum of each 5-year age group estimate.

In all cases, population numbers have been rounded to the nearest 100 . Where numbers for any group are equal to ten or less, these numbers are reported as $\leq 10$.

\subsection{Analysis}

The number of people aged 55+ years living with physical frailty (and pre-frailty) is reported by age group and gender. The number of people living alone by frailty status is also provided. Also included is a breakdown of frailty status by county. The data provided indicate the percentage of non-frail, pre-frail and frail for each county from TILDA 2018, as a proportion of the total population of the Republic of Ireland based on the CSO 2016 Census data for each age group. In the final section, the numbers of people in receipt of informal care (e.g. help from a spouse/partner, child, relative or other) and formal support services in the community (e.g. home help, personal care, meals-on-wheels and home care packages) are reported by frailty status at Wave 5 of the TILDA study.

\section{In light of the new HSE 'Guidance on coccooning to protect people over 70 years and those extremely medically vulnerable from COVID-19' which came into effect from midnight on March 28th 2020, this report will also provide information in relation to frailty on adults aged 70 and over.}




\section{Population estimates of adults aged $55+$ years in Ireland - CSO (2016) and TILDA (2018)}

Table 1 provides a distribution, by 5 -year age bands and gender, of the population estimates of the Republic of Ireland from CSO Census data (2016) and the corresponding distribution of TILDA participant numbers at Wave 5 (2018).

Table 1. Population estimates of adults aged 55+ years in Ireland - CSO (2016) and TILDA (2018)

\begin{tabular}{|c|c|c|}
\hline & CSO 2016 & TILDA 2018 \\
\hline \multicolumn{3}{|l|}{ Male } \\
\hline $55+$ years & 549,393 & 2,285 \\
\hline $70+$ years & 191,876 & 1,136 \\
\hline 55 - 59 years & 133,858 & 182 \\
\hline $60-64$ years & 118,698 & 503 \\
\hline 65 - 69 years & 104,961 & 464 \\
\hline $70-74$ years & 79,501 & 419 \\
\hline 75 - 79 years & 54,117 & 345 \\
\hline 80 - 84 years & 35,196 & 223 \\
\hline 85 years and over & 23,062 & 149 \\
\hline \multicolumn{3}{|l|}{ Female } \\
\hline $55+$ years & 597,132 & 2,862 \\
\hline $70+$ years & 234,455 & 1,346 \\
\hline 55 - 59 years & 136,244 & 308 \\
\hline $60-64$ years & 120,158 & 644 \\
\hline 65 - 69 years & 106,275 & 564 \\
\hline 70 - 74 years & 82,771 & 532 \\
\hline 75 - 79 years & 61,350 & 353 \\
\hline $80-84$ years & 45,841 & 232 \\
\hline $85+$ years & 44,493 & 229 \\
\hline \multicolumn{3}{|l|}{ Total } \\
\hline $55+$ years & $1,146,525$ & 5,147 \\
\hline $70+$ years & 426,331 & 2,482 \\
\hline 55 - 59 years & 270,102 & 490 \\
\hline 60 - 64 years & 238,856 & 1,147 \\
\hline $65-69$ years & 211,236 & 1,028 \\
\hline 70 - 74 years & 162,272 & 951 \\
\hline 75 - 79 years & 115,467 & 698 \\
\hline 80 - 84 years & 81,037 & 455 \\
\hline $85+$ years & 67,555 & 378 \\
\hline
\end{tabular}




\section{Physical Frailty Estimates by Age and Sex}

The prevalence, or the proportion of the community-dwelling population aged $55+$ and $70+$ years, by frailty status at TILDA Wave 5 and extrapolated to the population of the Republic of Ireland based on the CSO 2016 Census data for each age group, is provided in Figure 1 and Table 2. The prevalence of physical frailty increases with advancing age, from $11 \%$ in those aged $55+$ years, to $15 \%$ among those aged $65+$ years, to $19 \%$ among those aged $70+$ years. The highest prevalence of frailty is among those aged $75+, 80+$ and $85+$ years at $25 \%, 35 \%$ and $46 \%$ respectively. The equivalent numbers are: $126,100(55+) ; 89,500$ (65+); 80,600 (70+); 63,900 (75+); 48,800 (80+); and 31,100 (85+). These data indicated that frailty (and pre-frailty) were common among older adults in Ireland. The 80,600 people living with frailty and aged $70+$ years may require support in the community in terms of providing informal and formal community support services during the 'cocooning' period of the COVID-19 public health emergency.

The prevalence of frailty among men and women aged $55+$ and $70+$ years is presented in Figures 2 and 3 and Table 2. There are more women than men living with frailty in Ireland: $12.3 \%$ vs. $9.7 \%$ among those aged $55+$, and $20.3 \%$ vs. $17.5 \%$ among those aged $70+$. Conversely of the 126,100 living with frailty in Ireland, $56.2 \%(70,900)$ aged $55+$ years and $54.7 \%(44,000)$ aged $70+$ years are female. These data support the documented relationship between increasing prevalence of frailty among women compared to men and is a common finding internationally.

Figure 1. Prevalence of physical frailty in the total population aged $55+$ years.

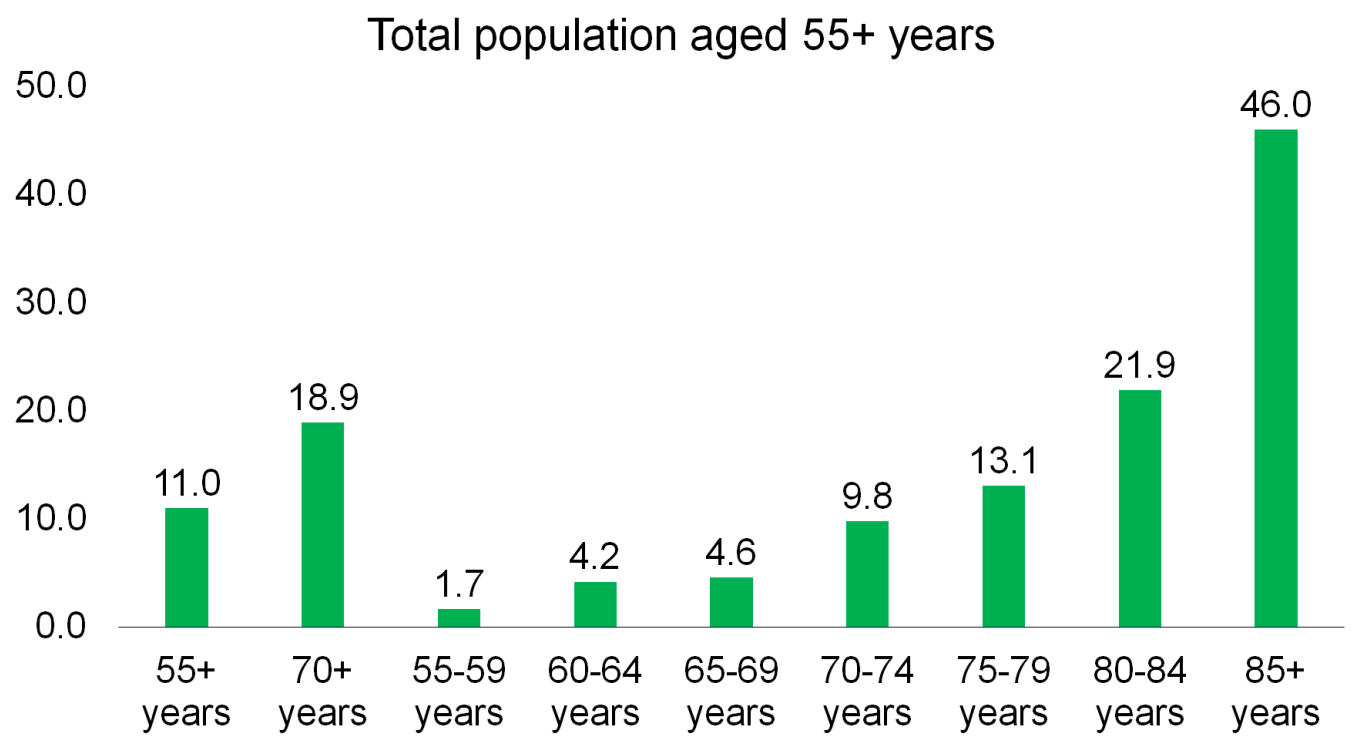


Figure 2. Prevalence of physical frailty in males aged 55+ years.

\section{Males aged $55+$ years}

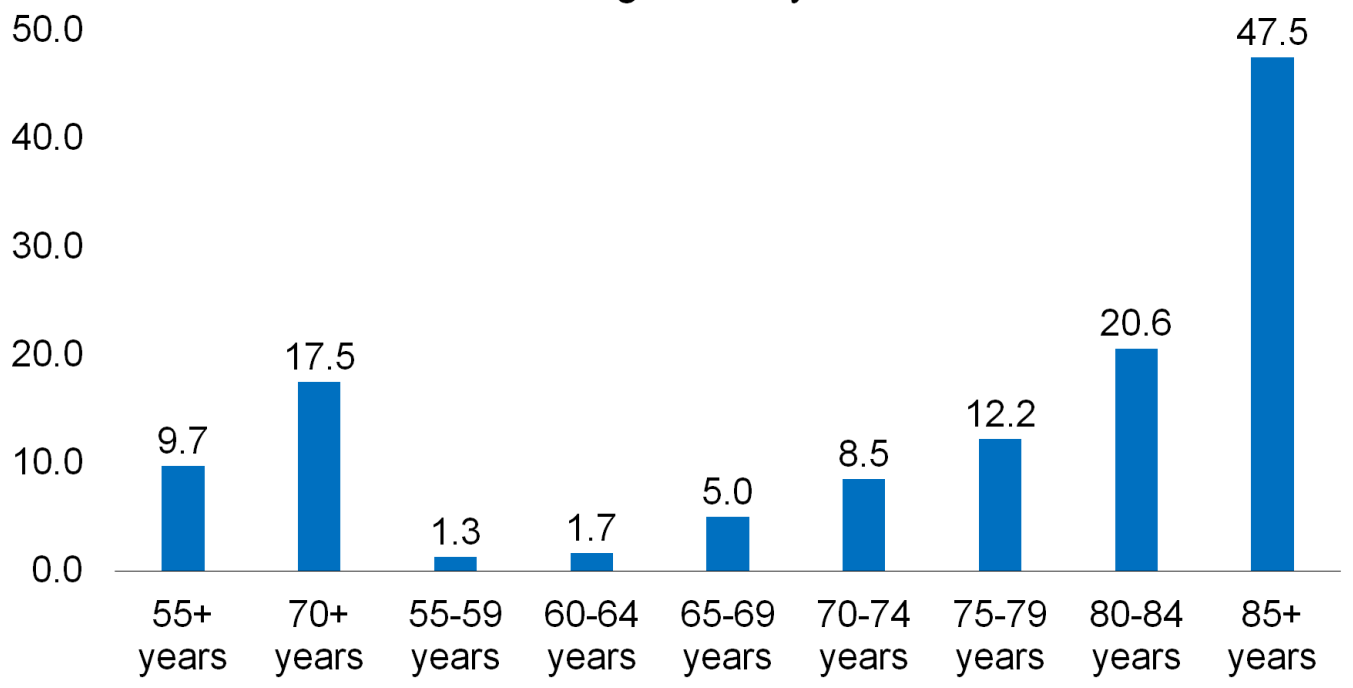

Figure 3. Prevalence of physical frailty in females aged 55+ years.

50.0

Females aged $55+$ years

40.0

30.0

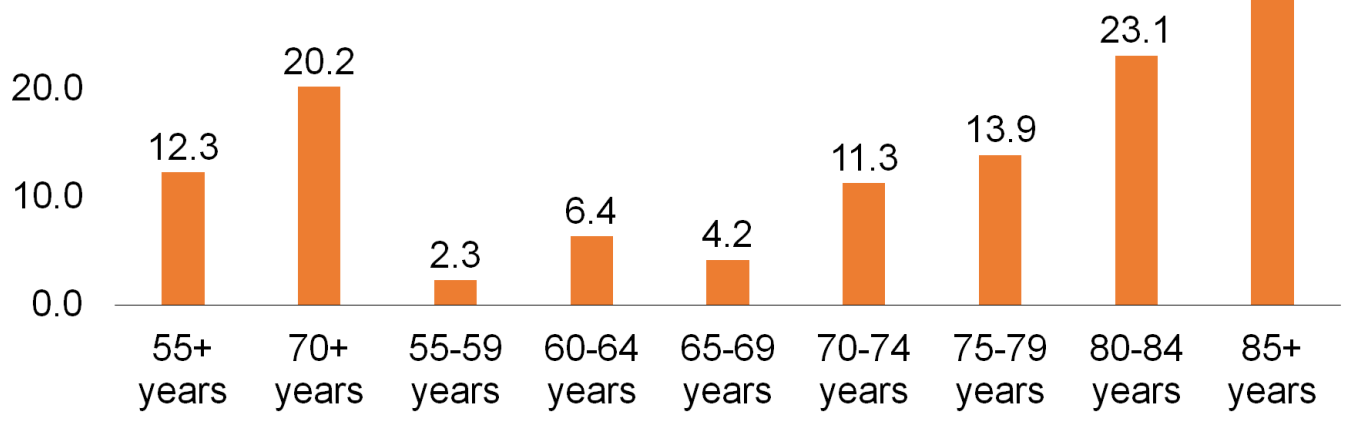



은

$\frac{0}{0}$

ก

ह

$\frac{\pi}{\frac{\pi}{0}}$

d

ह

(1)

ฐ

$\frac{\pi}{3}$

8

ษ

$\stackrel{2}{2}$

ป

ำ

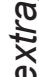

$\infty$

จ

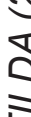

ㅋ

$\triangleq$

촌

ชิ

త্

क

4

बำ

ভ

$\frac{1}{2}$

एव

i

$\frac{1}{\frac{1}{0}}$

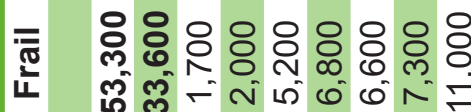

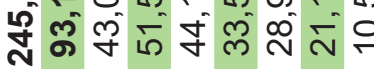
กั

苟

نำ

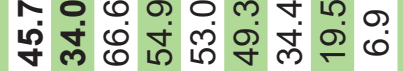

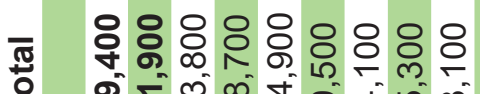

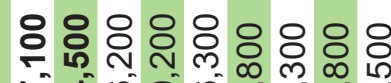

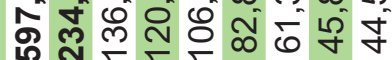

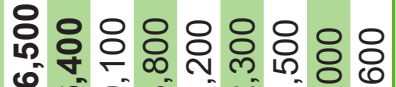

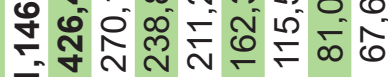

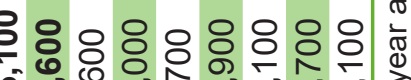
งิ

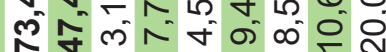

융유윰유유유 กิ

008

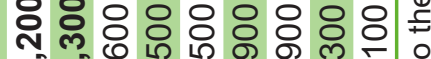

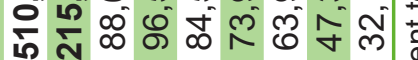

웅융융ㅇㅇㅇ ฝึ่

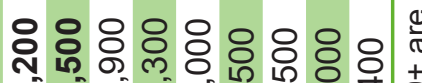

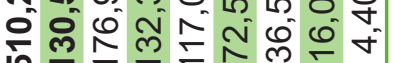
in $F-F N$

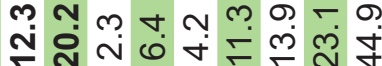

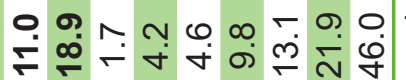

L m $\infty 000 m 0$

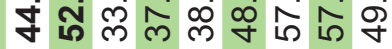

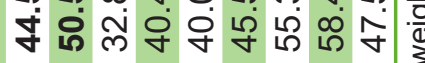

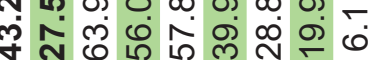

น

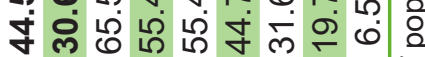

पㅇ

등 $\sum^{\frac{2}{2}}$

. 言 


\section{Physical Frailty and Living Alone by Age}

The prevalence of frailty among adults who live alone aged $55+$ and $70+$ years, and by 5 -year age bands, are summarised in Figure 4 and Table 3. Overall, the prevalence of frailty among adults who lived alone increased with age, from $16.4 \%$ among those aged $55+$ years to $28.1 \%$ among those age $70+$ years. The highest prevalence was among those aged $85+$ years. The equivalent numbers are: 17,500 (55+); 12,200 (70+) and 6,400 $(85+)$. These data indicate that significant numbers of adults living on their own are also living with frailty. It is likely that those 12,200 people living alone with frailty and aged $70+$ years may need to be further prioritised in terms of providing informal and formal community support services during the 'cocooning' period of the COVID-19 public health emergency.

Figure 4. Prevalence of physical frailty among those living alone in the population aged $55+$ years.

70.0

60.0

50.0

40.0

30.0

20.0

10.0

0.0

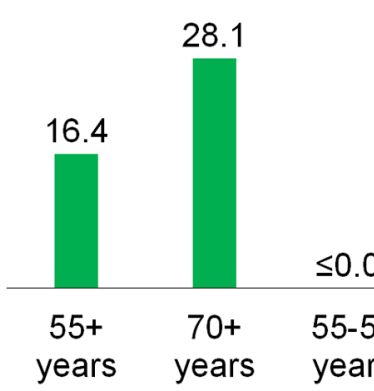

Living Alone and Frailty aged 55+ years

64.2

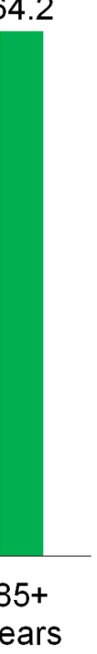


Table 3. Percentage prevalence of living alone by frailty status in TILDA (2018) extrapolated to CSO population estimate data from 2016.

\begin{tabular}{|c|c|c|c|c|c|c|c|c|}
\hline \multirow[b]{2}{*}{ Age Group } & \multicolumn{3}{|c|}{ TILDA (\%, 2018) } & \multicolumn{5}{|c|}{ CSO (n, 2016) } \\
\hline & Non-frail & Pre-frail & Frail & Non-frail & Pre-frail & Frail & Total & Total Alone \\
\hline \multicolumn{9}{|l|}{ Total } \\
\hline $55+$ years & 42.5 & 41.1 & 16.4 & 10.8 & 45,500 & 44,000 & 17,600 & 107,100 \\
\hline $70+$ years & 27.6 & 44.3 & 28.1 & 10.4 & 12,000 & 19,200 & 12,200 & 43,400 \\
\hline 55 - 59 years & 42.7 & 57.3 & $\leq 0.01$ & 6.7 & 7,700 & 10,400 & $\leq 10$ & 18,100 \\
\hline 60 - 64 years & 59.1 & 37.0 & 3.9 & 9.9 & 14,000 & 8,700 & 900 & 23,600 \\
\hline 65 - 69 years & 52.7 & 34.9 & 12.4 & 10.4 & 11,600 & 7,700 & 2,700 & 22,000 \\
\hline $70-74$ years & 44.8 & 37.5 & 17.7 & 8.9 & 6,500 & 5,400 & 2,600 & 14,400 \\
\hline 75 - 79 years & 17.8 & 74.9 & 7.3 & 8.8 & 1,800 & 7,600 & 700 & 10,200 \\
\hline 80 - 84 years & 43.5 & 22.5 & 34.0 & 11 & 3,900 & 2,000 & 3,000 & 8,900 \\
\hline $85+$ years & 3.0 & 32.7 & 64.2 & 14.7 & 300 & 3,200 & 6,400 & 9,900 \\
\hline
\end{tabular}

*Note due to the application of population weights, weighted estimates for $55+$ and $70+$ are not equivalent to the sum of each 5-year age group estimate. 


\section{Physical Frailty Estimates by County}

The prevalence of frailty for each county from TILDA 2018, as a proportion of the total population of the Republic of Ireland, based on the CSO 2016 Census data for the 55+ and $70+$ age groups, are presented in Figures 5 and 6 . The within county percentage and population estimates of those living with frailty in the $55+$ and $70+$ age groups are summarised in Table 4 and 5.

Among those aged $55+$ years, the counties with the highest numbers living with frailty, as a proportion of the total population of Ireland, are Dublin $(2.4 \% ; 27,600)$, Cork $(1.7 \%$; $19,400)$, Limerick $(0.9 \% ; 10,500)$ and Wexford $(0.5 \% ; 6,000)$. The counties with the lowest populations living with frailty are Offaly $(<0.1 \% ; 200)$, Carlow $(<0.1 \% ; 900)$, Roscommon $(<0.2 \% ; 1,500)$ and Sligo $(<0.2 \% ; 1,600)$. See Figure 5.

Among those aged $70+$ years, the counties with the highest populations living with frailty, as a proportion of the total population of Ireland, are Dublin $(4.2 \% ; 18,000)$, Cork $(3.2 \%$; $13,500)$, Limerick $(1.2 \% ; 5,300)$ and Wexford $(0.9 \% ; 4,000)$. The counties with the lowest populations living with frailty are Offaly $(<0.1 \% ; 200)$, Carlow $(<0.1 \% ; 300)$, Longford $(<0.2 \% ; 800)$ and Donegal and Roscommon $(0.2 \% ; 1,000)$. See Figure 6.

By county, the highest prevalence of frailty was in Leitrim (29.8\%), Limerick (21.5\%), Cavan $(21.1 \%)$ and Monaghan (20.9\%) among those aged 55+ years. By county, the highest prevalence of frailty was in Leitrim (48.4\%), Cavan (42.1\%), Monaghan $(36.5 \%)$ and Limerick (29.1\%) among those aged 70+ years. See Tables 4 and 5.

As expected, the counties with the largest urban population centres have the highest concentrations of frail adults. Different community support strategies may be required in urban versus rural settings to support those aged $70+$ years who are cocooning and living with frailty during the COVID-19 public health emergency. 
Figure 5. Prevalence of physical frailty by county in the population aged $55+$ years $(n=1,146,525)$.

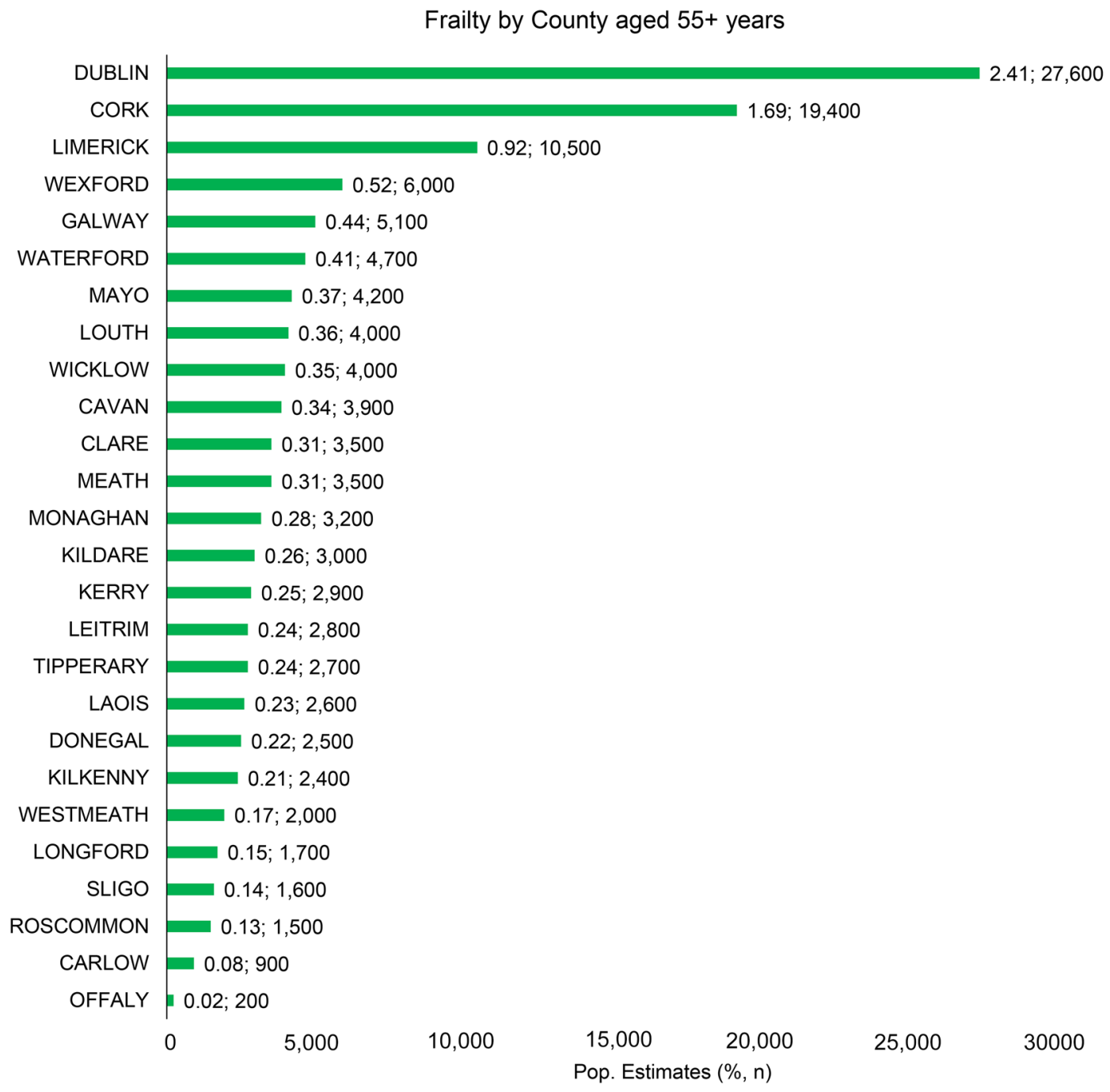


Table 4. Frailty status by county in the population aged $55+$ years $(n=1,146,525)$.

\begin{tabular}{|c|c|c|c|c|c|c|c|c|}
\hline County & $\begin{array}{c}\text { Population } \\
\text { (\%) }\end{array}$ & $\begin{array}{l}\text { Population } \\
\text { (N) }\end{array}$ & $\begin{array}{c}\text { Non-frail } \\
\%\end{array}$ & $\begin{array}{c}\text { Pre-frail } \\
\%\end{array}$ & $\begin{array}{l}\text { Frail } \\
\%\end{array}$ & $\begin{array}{c}\text { Non-frail } \\
\mathrm{N}\end{array}$ & $\begin{array}{l}\text { Pre-frail } \\
\qquad \mathrm{N}\end{array}$ & $\begin{array}{l}\text { Frail } \\
\mathrm{N}\end{array}$ \\
\hline DUBLIN & 25.82 & 296,000 & 47.10 & 43.58 & 9.32 & 139,400 & 129,000 & 27,600 \\
\hline CORK & 11.51 & 132,100 & 40.16 & 45.14 & 14.70 & 53,100 & 59,600 & 19,400 \\
\hline LIMERICK & 4.29 & 49,100 & 28.15 & 50.40 & 21.45 & 13,800 & 24,800 & 10,500 \\
\hline WEXFORD & 3.40 & 39,000 & 25.58 & 58.95 & 15.47 & 10,000 & 23,000 & 6,000 \\
\hline GALWAY & 5.48 & 62,900 & 47.97 & 43.97 & 8.06 & 30,200 & 27,600 & 5,100 \\
\hline WATERFORD & 2.66 & 30,500 & 36.26 & 48.39 & 15.35 & 11,100 & 14,700 & 4,700 \\
\hline MAYO & 3.47 & 39,800 & 50.13 & 39.41 & 10.47 & 19,900 & 15,700 & 4,200 \\
\hline WICKLOW & 2.97 & 34100 & 45.66 & 42.41 & 11.93 & 15,600 & 14400 & 4100 \\
\hline LOUTH & 2.54 & 29,100 & 44.71 & 41.59 & 13.70 & 13,000 & 12,100 & 4,000 \\
\hline CAVAN & 1.64 & 18,800 & 39.81 & 39.08 & 21.11 & 7,500 & 7,400 & 3,900 \\
\hline CLARE & 2.76 & 31,700 & 50.56 & 38.47 & 10.97 & 16,000 & 12,200 & 3,500 \\
\hline MEATH & 3.45 & 39,600 & 45.87 & 45.19 & 8.93 & 18,200 & 17,900 & 3,500 \\
\hline MONAGHAN & 1.35 & 15,400 & 21.67 & 57.40 & 20.93 & 3,300 & 8,900 & 3,200 \\
\hline KILDARE & 3.79 & 43,400 & 49.25 & 43.84 & 6.91 & 21,400 & 19,000 & 3,000 \\
\hline KERRY & 3.84 & 44,000 & 53.86 & 39.55 & 6.58 & 23,700 & 17,400 & 2,900 \\
\hline LEITRIM & 0.83 & 9,500 & 42.71 & 27.54 & 29.76 & 4,100 & 2,600 & 2,800 \\
\hline TIPPERARY & 3.76 & 43,200 & 42.13 & 51.52 & 6.35 & 18,300 & 22,200 & 2,700 \\
\hline LAOIS & 1.59 & 18,200 & 55.16 & 30.56 & 14.28 & 10,000 & 5,600 & 2,600 \\
\hline DONEGAL & 3.77 & 43,200 & 46.72 & 47.41 & 5.87 & 20,200 & 20,500 & 2,500 \\
\hline KILKENNY & 2.22 & 25,400 & 38.07 & 52.36 & 9.57 & 9,700 & 13,300 & 2,400 \\
\hline WESTMEATH & 1.82 & 20,900 & 61.06 & 29.26 & 9.68 & 12,800 & 6,100 & 2,000 \\
\hline LONGFORD & 0.91 & 10,400 & 47.92 & 35.98 & 16.10 & 5,000 & 3,700 & 1,700 \\
\hline SLIGO & 1.63 & 18,700 & 49.32 & 42.09 & 8.59 & 9,200 & 7,900 & 1,600 \\
\hline ROSCOMMON & 1.65 & 18,900 & 37.54 & 54.50 & 7.96 & 7,100 & 10,300 & 1,500 \\
\hline CARLOW & 1.17 & 13,500 & 43.15 & 50.61 & 6.24 & 5,800 & 6,800 & 900 \\
\hline OFFALY & 1.67 & 19,100 & 77.01 & 22.17 & 0.82 & 14,700 & 4,200 & 200 \\
\hline
\end{tabular}


TILDA Report on Population Estimates of Physical Frailty in Ireland to Inform Demographics for Over 50s in Ireland during the COVID-19 Pandemic

Figure 6. Prevalence of physical frailty by county in the population aged $70+$ years $(n=426,400)$.

Frailty by County aged $70+$ years

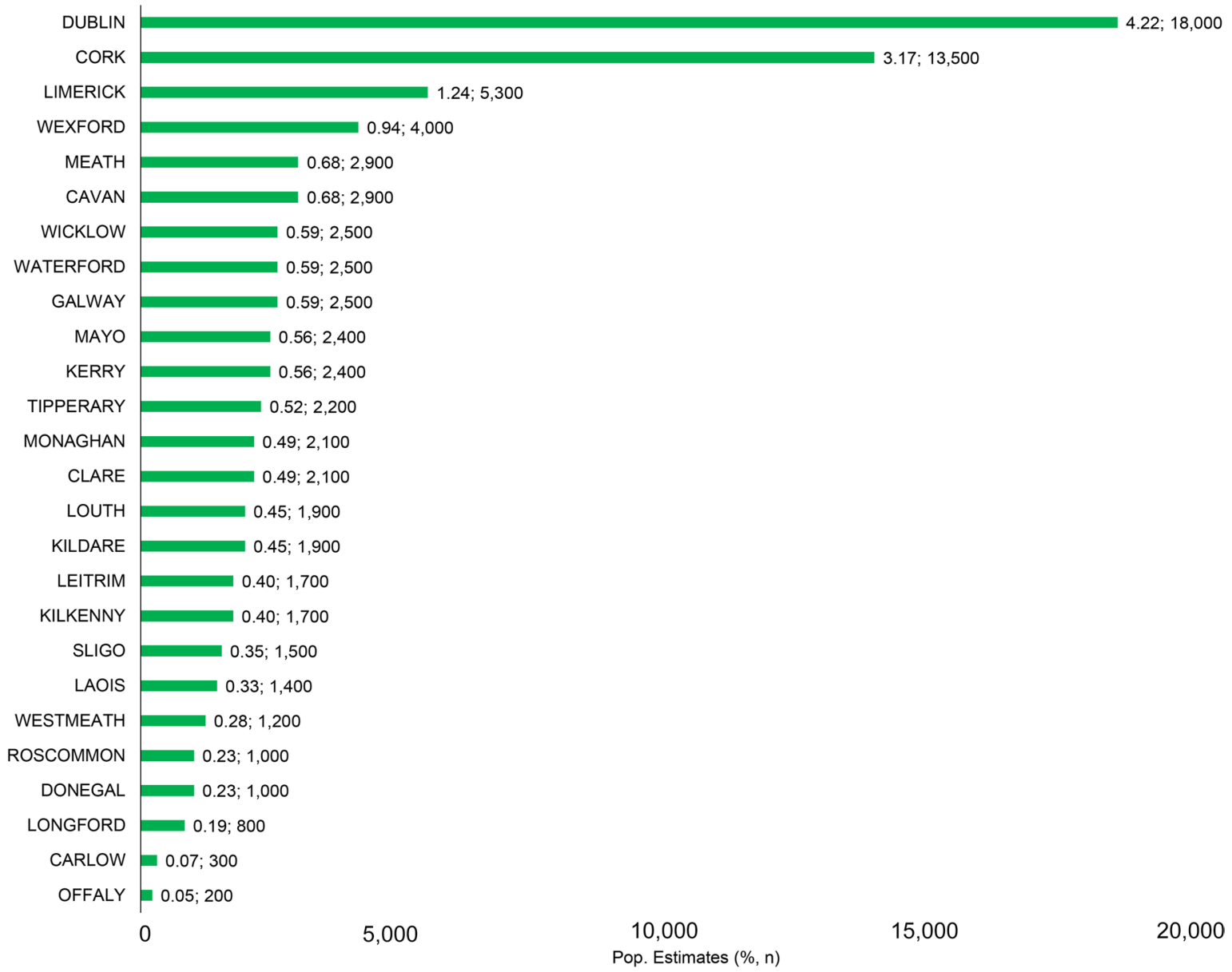


Table 5. Frailty status by county in the population aged $70+$ years $(n=426,331)$.

\begin{tabular}{|c|c|c|c|c|c|c|c|c|}
\hline County & $\begin{array}{l}\text { Population } \\
\text { (\%) }\end{array}$ & $\begin{array}{l}\text { Population } \\
\text { (N) }\end{array}$ & $\begin{array}{c}\text { Non-frail } \\
\%\end{array}$ & $\begin{array}{l}\text { Pre-frail } \\
\qquad \%\end{array}$ & $\begin{array}{l}\text { Frail } \\
\%\end{array}$ & $\begin{array}{c}\text { Non-frail } \\
\mathrm{N}\end{array}$ & $\begin{array}{c}\text { Pre-frail } \\
\text { N }\end{array}$ & $\begin{array}{l}\text { Frail } \\
\mathrm{N}\end{array}$ \\
\hline DUBLIN & 26.34 & 112,300 & 32.64 & 51.32 & 16.04 & 36,700 & 57,600 & 18,000 \\
\hline CORK & 11.68 & 49,800 & 30.43 & 42.46 & 27.12 & 15,200 & 21,100 & 13,500 \\
\hline LIMERICK & 4.25 & 18,100 & 20.56 & 50.32 & 29.12 & 3,700 & 9,100 & 5,300 \\
\hline WEXFORD & 3.45 & 14,700 & 12.59 & 60.17 & 27.24 & 1,900 & 8,800 & 4,000 \\
\hline CAVAN & 1.64 & 7,000 & 35.11 & 22.77 & 42.12 & 2,500 & 1,600 & 2,900 \\
\hline MEATH & 3.14 & 13,400 & 34.75 & 43.68 & 21.57 & 4,700 & 5,800 & 2,900 \\
\hline GALWAY & 5.51 & 23,500 & 31.73 & 57.61 & 10.66 & 7,500 & 13,500 & 2,500 \\
\hline WATERFORD & 2.74 & 11,700 & 29.68 & 49.26 & 21.06 & 3,500 & 5,700 & 2,500 \\
\hline WICKLOW & 2.89 & 12,300 & 36.55 & 42.98 & 20.47 & 4,500 & 5,300 & 2,500 \\
\hline KERRY & 3.87 & 16,500 & 26.80 & 58.55 & 14.65 & 4,400 & 9,700 & 2,400 \\
\hline MAYO & 3.59 & 15,300 & 41.48 & 43.09 & 15.43 & 6,300 & 6,600 & 2,400 \\
\hline TIPPERARY & 3.87 & 16,500 & 22.11 & 64.66 & 13.23 & 3,600 & 10,700 & 2,200 \\
\hline CLARE & 2.69 & 11,500 & 34.05 & 47.51 & 18.44 & 3,900 & 5,500 & 2,100 \\
\hline MONAGHAN & 1.34 & 5,700 & 19.04 & 44.45 & 36.51 & 1,100 & 2,500 & 2,100 \\
\hline KILDARE & 3.21 & 13,700 & 27.31 & 58.93 & 13.76 & 3,700 & 8,100 & 1,900 \\
\hline LOUTH & 2.51 & 10,700 & 27.71 & 54.34 & 17.95 & 3,000 & 5,800 & 1,900 \\
\hline KILKENNY & 2.20 & 9,400 & 24.60 & 57.19 & 18.21 & 2,300 & 5,400 & 1,700 \\
\hline LEITRIM & 0.87 & 3,700 & 25.79 & 25.85 & 48.36 & 1,000 & 1,000 & 1,700 \\
\hline SLIGO & 1.67 & 7,100 & 22.24 & 56.61 & 21.15 & 1,600 & 4,000 & 1,500 \\
\hline LAOIS & 1.50 & 6,400 & 27.69 & 50.53 & 21.79 & 1,800 & 3,200 & 1,400 \\
\hline WESTMEATH & 1.78 & 7,600 & 46.87 & 37.06 & 16.07 & 3,600 & 2,800 & 1,200 \\
\hline DONEGAL & 3.94 & 16,800 & 44.20 & 49.91 & 5.89 & 7,400 & 8,400 & 1,000 \\
\hline ROSCOMMON & 1.74 & 7,400 & 17.10 & 69.73 & 13.16 & 1,300 & 5,100 & 1,000 \\
\hline LONGFORD & 0.77 & 3,300 & 30.04 & 46.99 & 22.98 & 1,000 & 1,500 & 800 \\
\hline CARLOW & 1.15 & 4,900 & 41.13 & 52.14 & 6.73 & 2,000 & 2,600 & 300 \\
\hline OFFALY & 1.67 & 7,100 & 60.63 & 36.17 & 3.20 & 4,300 & 2,600 & 200 \\
\hline
\end{tabular}




\section{Physical Frailty by Informal Care and Formal Community Supports}

The percentage and numbers of people in receipt of informal care (e.g. help from a spouse/partner, child, relative or other) and formal support services in the community (e.g. home help, personal care, meals-on-wheels and home care packages) by frailty status are reported below. The 55+ age group is summarised in Figure 7 and Table 6, and the 70+ age group is summarised in Figure 8 and Table 7.

Of the 126,100 adults aged 55+ living with frailty: $72,100(57.2 \%)$ do not receive any form of informal care or formal community support service; $38,600(30.6 \%)$ receive informal care from a family member or friend; and 34,700 (27.5\%) receive formal community support services. Of those who received formal community support services: 12,500 $(9.9 \%)$ receive public home help; 10,800 (8.6\%) receive a public personal care attendant; $5,400(4.3 \%)$ receive public meals-on-wheels; and 5,000 (4.0\%) are in receipt of a home care package. Among the 55+ age group, 10,600 (8.3\%) pay for private home help or a personal care attendant services.

Of the 80,600 adults aged $70+$ years living with frailty: $44,500(55.2 \%)$ do not receive any form of informal care or formal community support service; $24,800(30.8 \%)$ receive informal care from a family member or friend and $26,100(32.4 \%)$ receive formal community support services. Of those who received formal community support services: $9,600(12.1 \%)$ receive public home help; $8,200(10.2 \%)$ receive a public personal care attendant; $4,300(5.3 \%)$ receive public meals-on-wheels and 3,600 (4.5\%) are in receipt of a home care package. Among the 70+ age group, 7,600 (9.4\%) pay for private home help or a personal care attendant services.

The TILDA sampling frame does not include people with dementia at baseline or people living in nursing homes, and as such these data may underestimate numbers in receipt of both informal care and formal community support services for the total population aged $55+$ years in Ireland.

Despite this, it would appear that there is a significant proportion of unmet need among those living with frailty, even among the medically vulnerable group aged 70+ year who will be cocooning over coming two weeks and potentially over a longer period. This is suggested by the finding that over half of those aged 70+ years and living with frailty did not report receiving any informal care or formal support. 
Figure 7. Percentage of frail people aged 55+ years in receipt of Community Supports.

Access to Community Supports by Frailty aged $55+$ years

No Formal or Informal Care

Any Formal Care

Informal Care

Public Home Help

Public Personal Care

Private Home Help/Personal Care

Public Meals-on-Wheels

Public Home Care Package

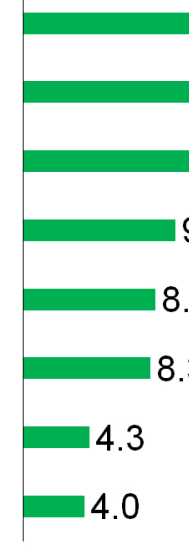

0.0

10.0

20.0

30.0

40.0

$50.0 \quad 60.0$

Table 6. Percent aged 55+ years living with pre-frailty and frailty in receipt of informal care and formal community supports by frailty status in TILDA (2018), extrapolated to CSO population estimates data (2016).

\begin{tabular}{|l|c|c|c|c|}
\hline & \multicolumn{2}{|c|}{ TILDA (\%, 2018) } & \multicolumn{2}{c|}{ CSO (n, 2016) } \\
\hline & Pre-frail & Frail & Pre-frail & Frail \\
\hline Population 55+ years & 44.5 & 11.0 & 510,200 & 126,100 \\
\hline No Formal or Informal Care & 89.7 & 57.2 & 457,700 & 72,100 \\
\hline Any Formal Care & 6.5 & 27.5 & 33,200 & 34,700 \\
\hline Any Informal Care & 5.5 & 30.63 & 27,800 & 38,600 \\
\hline Public Home Help & 2.2 & 9.9 & 11,200 & 12,500 \\
\hline Public Personal Care & 0.6 & 8.6 & 3,100 & 10,800 \\
\hline Private Home Help/Personal Care & 4.0 & 8.3 & 20,400 & 10,500 \\
\hline Public Meals-on-Wheels & 0.3 & 4.3 & 1,500 & 5,400 \\
\hline Public Home Care Package & $\leq 0.01$ & 4 & $\leq 10$ & 5,000 \\
\hline
\end{tabular}

* The TILDA sampling frame does not include people with dementia at baseline or people living in nursing homes and as such this data may underestimate numbers in receipt of both informal care and formal community support services for the total population aged $55+$ years in Ireland. 
Figure 8. Percentage of frail people aged 70+ years in receipt of Community Supports.

Access to Community Supports by Frailty aged $70+$ years

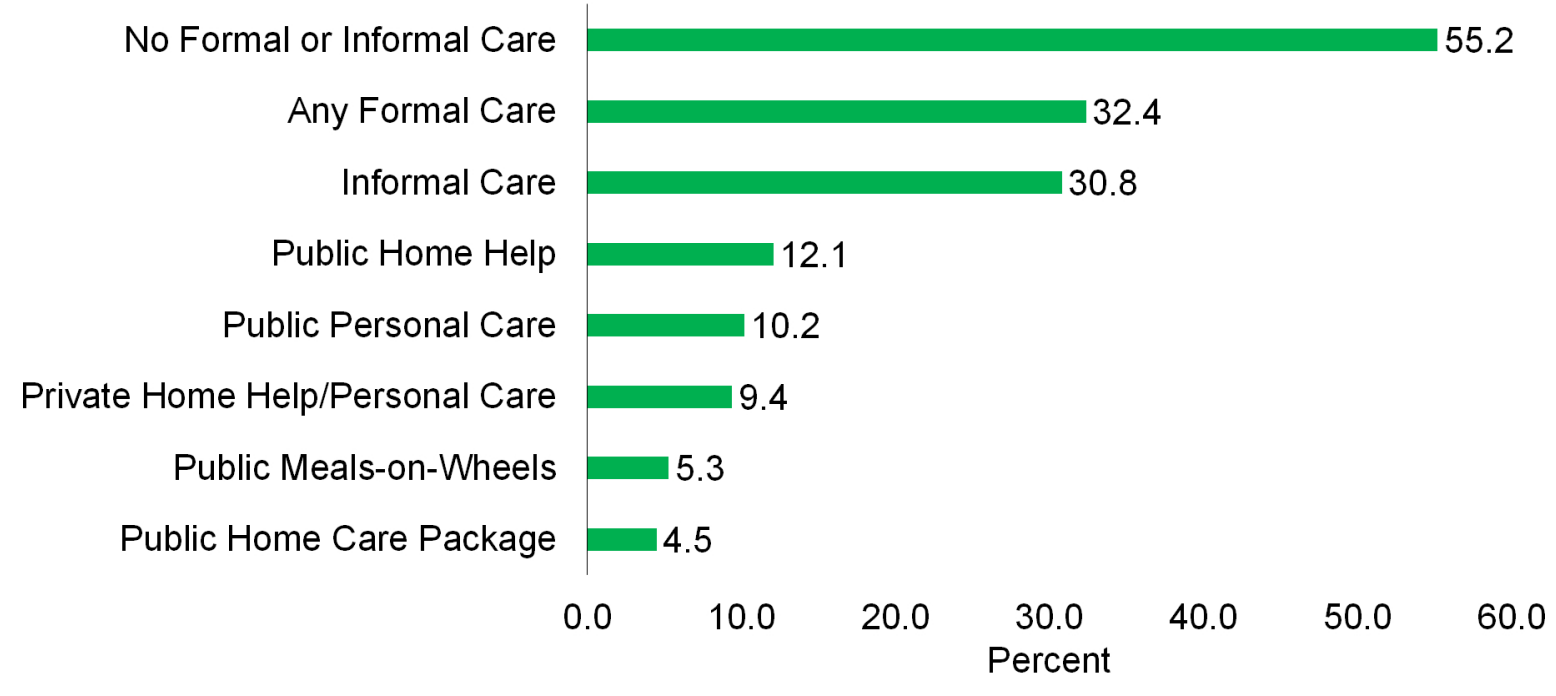

Table 7. Percent aged 70+ years living with pre-frailty and frailty in receipt of informal care and formal community supports by frailty status in TILDA (2018), extrapolated to CSO population estimates data (2016).

\begin{tabular}{|l|c|c|c|c|}
\hline & \multicolumn{2}{|c|}{ TILDA (\%, 2018) } & \multicolumn{2}{c|}{ CSO (n, 2016) } \\
\hline & Pre-frail & Frail & Pre-frail & Frail \\
\hline Population 70+ years & 50.5 & 18.9 & 215,300 & 80,600 \\
\hline No Formal or Informal Care & 83.7 & 55.2 & 180,200 & 44,500 \\
\hline Any Formal Care & 11.7 & 32.4 & 25,200 & 26,100 \\
\hline Any Informal Care & 7.5 & 30.8 & 16,100 & 24,800 \\
\hline Public Home Help & 4.0 & 12.1 & 8,600 & 9,800 \\
\hline Public Personal Care & 1.1 & 10.2 & 2,400 & 8,200 \\
\hline Private Home Help/Personal Care & 7.4 & 9.4 & 15,900 & 7,600 \\
\hline Public Meals-on-Wheels & 0.5 & 5.3 & 1,100 & 4,300 \\
\hline Public Home Care Package & $\leq 0.01$ & 4.5 & $\leq 10$ & 3,600 \\
\hline
\end{tabular}

* The TILDA sampling frame does not include people with dementia at baseline or people living in nursing homes, and as such these data may underestimate numbers in receipt of both informal care and formal community support services for the total population aged 70+ years in Ireland. 


\section{Conclusions}

This report demonstrates that physical frailty is prevalent at 1 in 9 adults aged $55+$ years in the Republic of Ireland. It is striking that almost 1 in 5 of adults aged $70+$ years are living with frailty. This is the age group which is considered to be 'extremely medically vulnerable' to the adverse health impacts of contracting COVID-19, and has been advised by the Irish Government and HSE to participate in 'cocooning' during the COVID-19 public health emergency. For those over 70 years and living with frailty, the risks of contracting the infection and subsequent admission to hospital, critical/intensive care and risk of death are even greater. The data presented in this report also suggest that there is significant unmet need in relation to people living alone with frailty and the provision of informal and formal care supports in the community.

The impact of frailty on the Irish health and social care system is considerable (8) and will be greatly exacerbated by the impact of the COVID-19 pandemic. The significance of frailty as an impediment to healthy ageing was highlighted at a focus meeting on 'Frailty and Intrinsic Capacity' by the World Health Organisation (WHO) Clinical Consortium on Healthy Ageing in December 2016 (14). The significance of frailty to healthy ageing, health care planning and delivery in Ireland is recognised by the National Clinical Care Programme for Older People (NCPOP) and the Integrated Care Programme for Older People (ICPOP). A National Frailty Education Programme, in partnership with TILDA, was initiated in 2017 to train health professionals to understand the risk factors for frailty enabling them to implement programmes for early detection, prevention and management (15). In 2016 , the WHO Clinical Consortium on Healthy Ageing stated that active case findings of older people with frailty is essential for the reorientation of health services to meet people's needs; proactive identification of people in the community at risk of frailty provides opportunities to intervene and so prevent or delay functional decline and disability (14). In the context of COVID-19, the proactive identification of people with frailty in the acute setting will also become an imperative when decisions in relation to transfer to resource limited critical care pathways will need to be made (5).

Frailty is not an inevitable consequence of ageing: 3 in 5 people aged $75+$ and 1 in 2 people aged $85+$ years are classified as robust or pre-frail. Frailty is a dynamic process, and people can experience positive transitions reverting to pre-frailty from frailty and to robustness from pre-frailty. Frailty is modifiable; it may be delayed, halted and even reversed with timely and appropriate prevention, detection and intervention strategies. 'Cocooning', though difficult, is a very real opportunity to protect medically vulnerable 
TILDA Report on Population Estimates of Physical Frailty in Ireland to Inform Demographics for Over 50s in Ireland during the COVID-19 Pandemic

adults aged $70+$ years in Ireland, particularly those living with frailty who are at high risk of disability and death due to COVID-19 infection. Our people aged 70 and over are the fabric of our society (16). This report highlights the need to facilitate more informal community supports, while also proactively increasing healthcare service planning and delivery for the medically vulnerable population aged $70+$ years to help them to remain safely cocooned from COVID-19. 


\section{References}

1. Fried LP, Tangen CM, Walston J, Newman AB, Hirsch C, Gottdiener J, et al. Frailty in older adults: evidence for a phenotype. J Gerontol A Biol Sci Med Sci. 2001;56(3):M146-56.

2. Clegg A, Young J, lliffe S, Rikkert MO, Rockwood K. Frailty in elderly people. Lancet. 2013;381(9868):752-62.

3. Fit for Frailty - Consensus best practice guidance for the care of older people living in community and outpatient settings. British Geriatric Society 2014.

4. Guidance on cocooning to protect people over 70 years and those extremely medically vulnerable from COVID-19. Health Service Executive (HSE), Republic of Ireland. 27 March 2020. https://www.hpsc.ie/az/respiratory/coronavirus/novelcoronavirus/ guidance/vulnerablegroupsguidance/COVID-19\%20Guidance\%20for\%20 extremely\%20medically\%20vulnerable\%20V1.pdf

5. COVID-19 rapid guideline: critical care in adults. NICE guideline [NG159]. National Institute for Health and Care Excellence (NICE), UK. 25 March 2020. https://www.nice. org.uk/guidance/ng159/chapter/2-Admission-to-critical-care

6. Collard RM, Boter H, Schoevers RA, Oude Voshaar RC. Prevalence of frailty in community-dWelling older persons: a systematic review. J Am Geriatr Soc. 2012;60(8):1487-92.

7. HSE. Urgent Care Needs for Older People - Frailty at the Front Door 2017.

8. Roe L, Normand C, Wren MA, BroWne J, O'Halloran AM. The impact of frailty on healthcare utilisation in Ireland: evidence from the Irish longitudinal study on ageing. BMC Geriatr. 2017;17(1):203.

9. Gill TM, Gahbauer EA, Allore HG, Han L. Transitions between frailty states among community-living older persons. Arch Intern Med. 2006;166(4):418-23.

10. Fried LP, Ferrucci L, Darer J, Williamson JD, Anderson G. Untangling the concepts of disability, frailty, and comorbidity: implications for improved targeting and care. $\mathrm{J}$ Gerontol A Biol Sci Med Sci. 2004;59(3):255-63. 
11. Turner G, Clegg A, British Geriatrics S, Age UK, Royal College of General P. Best practice guidelines for the management of frailty: a British Geriatrics Society, Age UK and Royal College of General Practitioners report. Age Ageing. 2014;43(6):744-7.

12. Ellis G, Whitehead MA, Robinson D, O'Neill D, Langhorne P. Comprehensive geriatric assessment for older adults admitted to hospital: meta-analysis of randomised controlled trials. BMJ. 2011;343:d6553.

13. Sternberg SA, Wershof SchWartz A, Karunananthan S, Bergman H, Mark Clarfield A. The identification of frailty: a systematic literature review. J Am Geriatr Soc. 2011;59(11):2129-38.

14. WHO Clinical Consortium on Healthy Ageing. Topic focus: frailty and intrinsic capacity. Report of consortium meeting 1-2 December 2016 in Geneva S.

15. Lang D, Hoey C, O'Shea D, Whitty H. A National Frailty Education Programme. International Journal of Integrated Care. International Journal of Integrated Care 2017;17(5).

16. McGarrigle CA, Ward M, Scarlett S, Kenny RA. (2020) THE CONTRIBUTIONS OF THE OVER 70S TO IRISH SOCIETY: RESULTS FROM WAVE 5 OF THE IRISH LONGITUDINAL STUDY ON AGEING. https://www.doi.org/10.38018/TildaRe.2020-01 